\title{
Identificaciones y territorialización de migrantes quechuas de Bolivia en Caleta Olivia, Santa Cruz, Argentina ${ }^{1}$
}

\author{
Brígida Baeza ${ }^{2}$
}

\begin{abstract}
RESUMEN
Nuestro caso de análisis se ubica en la ciudad de Caleta Olivia, un centro urbano y petrolero del norte de la provincia de Santa Cruz (Argentina). En este artículo, nos proponemos aportar al campo de las denominadas "Geografías indígenas", desde el análisis de las formas espaciales que adquieren las diferenciaciones e identificaciones de un grupo de migrantes indígenas-bolivianos, considerando su adscripción indígena-quechua, su condición de clase, nacional y de género, en un contexto migratorio. Nos interesa analizar el modo en que las adscripciones indígenas y migrantes de estos individuos se intersectan de modo complejo en un contexto territorial urbano, diferente al del lugar de origen asociado mayormente al espacio rural cochabambino. En Caleta Olivia, los migrantes quechuas-bolivianos residen en su mayor parte en un área "alta" de la ciudad, el denominado "Barrio 3 de Febrero", territorio que aquí analizaremos tratando de captar su dinámica y complejidad.
\end{abstract}

Palabras clave: Migrantes, Caleta Olivia, bolivianos, quechua

\begin{abstract}
Our case study is located in the city of Caleta Olivia, an urban center and oil hub in northern Santa Cruz (Argentina). The propose of this article is to contribute to the field of "Indigenous Geography", by analyzing spatial aspects of differentiation and identification of a group of Indigenous-Bolivian migrants who identify as Quechua, including aspects of class, nationality and gender in the context of immigration. We are interested in analyzing how indigenous and migrant identities intersect in complex ways in the urban context, which is different from their places of origin, primarily rural areas of Cochabamba. In Caleta Olivia, Quechua-Bolivian migrants live mostly in a "high" sector of the city, called "Barrio 3 de febrero", an area whose dynamics and complexity are analyzed here.
\end{abstract}

Key words: migrants, Caleta Olivia, Bolivians, Quechua

\footnotetext{
1 Artículo recibido el 30 de abril de 2015, aceptado el 27 de julio de 2015 y corregido el 11 de septiembre de 2015 .
}

\footnotetext{
2 Consejo Nacional de Investigaciones Científicas y Técnicas / Instituto de Estudios Sociales y Políticos de la Patagonia, Universidad Nacional de la Patagonia San Juan Bosco (Argentina).

E-mail: brigida_baeza@hotmail.com
} 
La ciudad de Caleta Olivia (Santa Cruz, Argentina) pertenece a la denominada Cuenca del Golfo San Jorge y posee una base monoproductiva que gira en torno a la extracción petrolera. Alrededor de esta actividad, se gestó un tipo de poblamiento ligado a distintos procesos migratorios de características y orígenes diversos, siendo la heterogeneidad poblacional un aspecto constitutivo de la matriz societaria de esa ciudad. Resalta en su poblamiento la presencia de migrantes internos del noroeste argentino, precisamente catamarqueños y riojanos y, desde hace más de una década, grupos de migrantes bolivianos provenientes de -sobre todo- la región de Cochabamba, de la zona de Punata, más precisamente el área rural de Cuchupunata, siendo muchos de ellos y ellas hablantes quechua. Las adscripciones indígenas y migrantes de estos individuos se intersectan de modo complejo en un contexto territorial urbano, diferente al del lugar de origen, asociado mayormente al espacio rural. Ahí, muchos hombres se emplean en el rubro de la construcción y en servicios de transporte escolar o en agencias de taxis, o bien junto a las mujeres en las empresas pesqueras o en el comercio. Residen en su mayor parte en un área "alta" de la ciudad, el denominado "barrio 3 de febrero" $^{\prime 3}$, y tienen una activa participación religiosa católica, social y política a través de la asociación que los nuclea: "Patria Grande".

Si bien, nuestro caso de análisis se da en un contexto de segregación espacial, esta situación genera posibilidades de encuentro y reencuentro, donde se desarrolla un proceso de fortalecimiento político, de modo similar al analizado para el caso de mapuches residentes en barrios de Santiago de Chile (Gissi, 2004). En los contextos de movilidades campo-ciudad, se producen una serie de reacomodamientos a nivel socioeconómico en la vida de los migrantes, pero también identita-

\footnotetext{
3 La denominación del barrio refiere a la fecha en que se inauguró la Unión Vecinal en honor al aniversario de San Blas, santo de las dolencias de garganta. De acuerdo a la información provista por la Presidenta de la Unión Vecinal actual, la denominación se encuentra vinculada a la fuerte presencia de riojanos y catamarqueños devotos del santo. Conversación realizada con la presidenta de la Unión Vecinal del Barrio 3 de Febrero, Caleta Olivia, 29 de octubre de 2014.
}

rio. En el caso de las comunidades indígenas, el hecho de introducirse en la vida urbana genera una serie de cambios a nivel familiar, paisanal y barrial. En algunos casos, como el de "La Terminal" en Nicaragua, se generan espacios barriales etnizados en sí mismos (Bastos y Camus, 1995), al punto de que "el recién llegado" puede sentir la cercanía con su lugar de origen. Sin ánimo de agotar aquí la literatura existente sobre las problemáticas que generan las migraciones de poblaciones indígenas a los centros urbanos en América Latina, podemos mencionar el caso de las poblaciones mayas que llegan a la capital de Guatemala en un contexto migratorio que genera tanto pretensiones de "despojo cultural" como reafirmaciones étnicas (Camus, 2002: 65), así como los análisis para el caso de aimaras urbanos en La Paz, donde se activan los lazos étnicos y recompone una sociabilidad aimara urbana, experimentándose el ascenso social pero también el rechazo de la sociedad receptora (Albó, 1992).

La perspectiva teórica en la que nos ubicamos asume que el espacio urbano es un lugar de articulaciones sociales que pueden ser rastreadas mediante diversas estrategias analíticas, específicamente desde un enfoque geográfico. Dicho esto, el trabajo intentará 1) examinar/reconstruir tanto las diferenciaciones internas del grupo de migrantes indígenas-bolivianos-punateños, así como 2) indagar acerca de las representaciones de la sociedad receptora sobre los migrantes, desde una mirada socioantropológica. Teóricamente, nos ubicamos en el modo de abordaje del historiador que busca la "reconstrucción del tapiz" mediante el descubrimiento de indicios imperceptibles. Nos interesa complejizar nuestra mirada considerando estos grupos migrantes más allá de su adscripción nacional, reparando particularmente en su etnicidad, pensada como construcción dinámica que se modifica en el transcurso del viaje y la residencia en el nuevo territorio. De este modo, adquieren interés de análisis las prácticas cotidianas (Lindon, 2004), y la forma en que se apropian del espacio urbano, se inscriben en él, o sea, cómo se territorializan. Nuestra perspectiva recupera la mirada de la geografía constructivista que asume que el sujeto habitante construye lugares cotidianamente, y a la vez esos lugares también reconfiguran 
las identidades de los sujetos que los habitan (Lindon, 2007).

En este sentido, la geografía ofrece las herramientas conceptuales indicadas para analizar este tipo de procesos, a partir de la consideración de la imbricación de las diversas escalas (Harvey, 2007; Smith, 2012; Benedetti, 2011) que debemos tener en cuenta para el análisis de un grupo migratorio como el que aquí consideramos. Así también, se incorporarán al análisis conceptos como el de territorio que usaremos a lo largo del artículo, en un intento de aportar a un tipo de producción de conocimiento que contribuya a enriquecer nuestra mirada acerca del modo en que el uso de enunciados espaciales se vincula con la formación de subjetividades (Martínez Berríos, 2012). Recuperamos aquí la concepción de territorio desde su construcción social permanente, como resultado de la interacción entre

“...las estructuras objetivas del espacio (obras de las sociedades) con las estructuras cognitivas (que se traducen en imágenes, representaciones y distintas ideologías) individuales, aunque con esencia social, que dan forma a la conciencia de todo ser humano..." (Di Meo, 1999: 91).

El concepto de territorio debe ser acompañado por el de territorialidad como fenómeno que obedece a tres series de leyes imbricadas e interdependientes: las de la experiencia existencial de cada uno, las de la codeterminación dialéctica del sujeto y de su contexto social, las de la organización del espacio geográfico objetivado (Di Meo y Buleon, 2005). En definitiva, nos interesa destacar que el territorio no es un soporte material carente de temporalidad, sino que el territorio mismo es un proceso, constitutivo del entramado de relaciones sociales (Benedetti, 2011) que se recrean y construyen cotidianamente.

Nos interesa rescatar aquí los aportes de la geografía indígena (Hirtz, 2012; Martínez Berríos, 2012), en particular la perspectiva que observa el modo en que los espacios territoriales están cargados de sentido cultural de una etnia específica (Molina, 1995). En nuestro caso particular, nos interesa destacar la territorialidad quechua que se genera a partir de las relaciones entre los distintos integrantes de los grupos provenientes de la zona rural de Cochabamba. Las relaciones de vecindad, paisanaje, parentesco y múltiples vínculos que en algunos casos fueron previos al proceso migratorio y en otros se construyeron en el "3 de febrero". Sus prácticas espaciales plasmadas en la construcción de viviendas, calles, comercios, instituciones religiosas y de asociación, es posible observar cómo este grupo de migrantes construye territorialidad a partir de los lazos que los reúnen a diario y en especial frente a determinadas celebraciones y rituales. Nos interesa analizar el modo en que este grupo de migrantes que provienen de la zona rural de Cochabamba, viven el espacio (Claval, 2002), y construyen un tipo de territorio cuyos componentes remontan a su origen indígena.

Las geografías indígenas contribuyen a problematizar las características que adquieren los procesos migratorios de comunidades indígenas de base rural a centros urbanos industriales, en un desplazamiento que posee determinadas características, tales como la búsqueda de lugares elegidos por presentar menores fricciones que aquellos lugares donde el capitalismo ha generado encuentros heterogéneos y desiguales que pueden Ilevar a nuevas configuraciones de la cultura y el poder (Tsing, 2005). Así, los "lugares clásicos" como Buenos Aires, Mendoza, Córdoba, entre otras grandes urbes de Argentina, en ocasiones representan una "primera parada" en un desplazamiento que se extiende a lugares como Caleta Olivia, donde estos migrantes globalizados parecen encontrar espacios no solo de movilidad socioeconómica esperable para quien migra, sino también una serie de posibilidades que, por el contexto local y global, les permiten construir lazos donde el territorio es clave para poder explicar las particularidades de los grupos migrantes quechuas provenientes de Bolivia.

Consideramos necesario problematizar la noción de "barrio boliviano", "asentamiento", entre otras categorías que en realidad no son suficientes para analizar su forma de inserción territorial a través de la conformación de determinadas prácticas culturales y su "forma de ser boliviano-hablante quechua" en una sociedad urbana e industrial del norte santacruceño-argentino. En el caso de Caleta Olivia, se produce un proceso de apropiación 
del espacio urbano y de inscripción territorial que es necesario abordar desde una mirada interdisciplinaria que recupere tanto la cotidianeidad como las transformaciones que lleva adelante el grupo aquí analizado.

Ante esta situación, si la realidad a investigar se caracteriza por dificultades para ser observada, siempre existen huellas que permiten reconstruir los cambios y transformaciones culturales. A esta perspectiva de análisis, sumamos la necesidad de la perspectiva etnográfica buscando no solo observar, sino también interpretar y sobre todo comprender al Otro "desde adentro". Por eso, recorrer, preguntar, indagar, entrevistar se constituyó en el modo de abordar una problemática que, por sus características, es posible analizar considerando un corpus teórico asociado a captar sensibilidades e indicios enmarcados en las trayectorias de grupos migrantes de múltiples adscripciones identitarias. Entre junio de 2013 y septiembre de 2014, realizamos 12 entrevistas en profundidad a distintos miembros de la comunidad de migrantes bolivianos, representantes de la agencia estatal municipal y de otros grupos que se vinculan con el grupo protagonista de nuestra investigación, además de una serie de registros de observaciones en festividades y celebraciones, así como de momentos cotidianos como compartir un almuerzo. En ocasiones, las observaciones fueron de carácter participativo, tales como determinados hechos donde colaboramos en trámites ante instituciones estatales y que nos permitieron registrar diversos tipos de aceptabilidad u obstáculos para el desarrollo de las prácticas migrantes en nuestro caso de estudio.

El texto se estructura a partir de una caracterización general del proceso migratorio,

Figura $\mathrm{N}^{\circ} 1$

Migraciones quechuas de Bolivia a Caleta Olivia

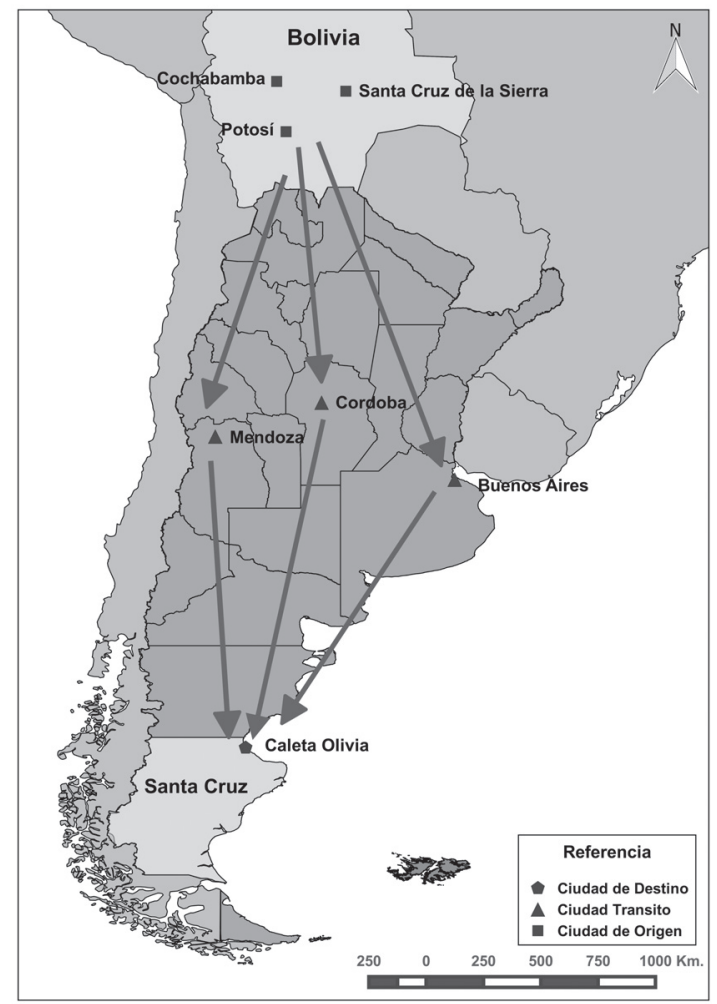

Fuente: Elaborado por Leonardo Schuler. 
a nivel nacional y regional, de comunidades quechuas procedentes mayormente de la región de Cochabamba en Bolivia, hacia el sur patagónico argentino, centralmente la ciudad de Caleta Olivia (Figura $N^{\circ} 1$ ). La segunda sección del artículo, en tanto, se enfoca en el Centro de Residentes Bolivianos de Caleta Olivia, que puede ser considerado como un lugar central en la recomposición de la sociabilidad quechua. Nos referimos en esta sección a la producción territorial quechua en Caleta Olivia a partir de distintas dimensiones tales como lo religioso y lo comercial. Por último, a modo de conclusión, incluimos nuestro análisis en un juego de escalas donde lo local y lo global se interrelacionan y manifiestan de modo complejo en el territorio.

\section{Migrantes quechuas de Bolivia en el contexto de una sociedad portuaria y petrolera}

Caleta Olivia surgió como una ciudad portuaria que sufrió importantes transformaciones con la expansión de la explotación petrolera en el contexto de la Gobernación Militar (1944-1955), durante el primer gobierno peronista. Actualmente, cuenta una población total de 51.733 habitantes, siendo la ciudad más poblada del Departamento Deseado que suma 107.630 habitantes, de los cuales 99.155 son argentinos y el resto se distribuye del siguiente modo ${ }^{4}$ :

\section{Cuadro $\mathrm{N}^{\circ} 1$}

Distribución de la población migratoria en Departamento Deseado, Santa Cruz, Bolivia.

\begin{tabular}{|l|r|}
\hline Población total nacida en el & 8.475 \\
\hline extranjero & 4.324 \\
\hline Bolivianos & 2.741 \\
Paraguayos & 648 \\
Otros grupos & 762 \\
\hline
\end{tabular}

Fuente: Elaboración propia en base a datos del Censo 2010

\footnotetext{
4 Los datos mencionados corresponden al Censo de población 2010, en el cual solo se cuenta con datos de población general por localidad, pero discriminados por origen solo se cuenta con información departamental. Censo 2010. INDEC.
}

De modo similar al caso de la ciudad vecina de Comodoro Rivadavia, en Caleta Olivia se puede observar de qué modo la noción de "tiempo de residencia" forma parte de las relaciones cotidianas (Baeza, 2013b), pero también posee su fundamento en determinadas legislaciones de acceso al empleo público ${ }^{5}$ o en otros ámbitos tales como la construcción. En las últimas décadas, se acrecentaron las diferenciaciones entre los Nacidos y Criados -NYC- y los Venidos y Quedados -VYQ- o bien denominados como "los nuevos"/ "los de afuera"; estas categorías nativas son generadas en las interacciones cotidianas por los grupos que se arrojan el papel de pioneros y fundadores, que pugnan por preservar espacios de dominio en la sociedad local. De modo similar a la situación de discriminación en el ejercicio de una ciudadanía plena, tal como lo aborda Rincón Gamba (2012) para el caso de Río Gallegos (Santa Cruz), donde migrantes internos y limítrofes no solo son sujetos desterritorializados por no residir en su lugar de origen, sino que a la vez son reterritorializados al apropiarse y transformar su nueva residencia. O bien el caso de Jujuy, donde el discurso sobre la etnicidad es de carácter político, y el hecho de haber nacido en el lugar no garantiza ser considerado un connacional, tal como el caso de los hijos de migrantes bolivianos que pueden seguir siendo considerados "bolivianos" (Karasik, 1992).

En el caso de Caleta Olivia, las diferenciaciones por "venir de afuera" no solo son experimentadas por parte de migrantes bolivianos, sino que forman parte de lo que sienten otros grupos de migrantes internos del país, tal como el caso de quienes provienen de provincias del noreste. Una mujer correntina comentaba, por ejemplo, que siente que el oriundo de Patagonia "es frío, defiende su lugar; me pasa muchas veces que marquen: "vos no sos de acá'". Nuestra entrevistada manifestó acerca de los NYC: "ellos quieren

\footnotetext{
5 Por mencionar solo un ejemplo, para el ingreso en el ejercicio de la docencia provincial se requiere tener como mínimo un año de residencia comprobada en la provincia de Santa Cruz, de acuerdo a la legislación vigente en el acuerdo 179/99. Ver: http://www.adosac.org.ar/index.php?option=com_k2 \&view=item\&layout=item\&id=27\&ltemid=245 (Consulta realizada el 16 de octubre de 2014).
} 
los trabajos del petróleo y la municipalidad" 6 . Entonces, los grupos migrantes logran conocer las características de la sociedad local, desarrollando prácticas que indican conocimiento y apropiación del modo de vida del nuevo lugar de residencia.

Por su parte, los primeros grupos migrantes bolivianos se instalaron en la ciudad en el contexto de construcción del Puerto Caleta Olivia, inaugurado en 1998. Muchos de los hombres "pioneros" trabajaron en las empresas constructoras y, luego, una vez en marcha las pesqueras, junto a las mujeres bolivianas, se emplearon en las mismas. Según un diagnóstico realizado en el marco del Plan Estratégico de Desarrollo Productivo Caleta Olivia del año 2009, por la Fundación Agencia de Desarrollo Caleta Olivia ${ }^{7}$, casi la mitad de la población ocupada se empleaba en el Sector Privado $(47,4 \%)$, luego seguía el Sector Público $(32,1 \%)$ y, por último, el Trabajo por cuenta propia $(17,9 \%)$. Los migrantes se encontraban con los menores índices de desocupación. Y en base a las observaciones realizadas, podemos destacar que los migrantes bolivianos -hombres y sobre todo mujeres- se concentran en ocupaciones en el Sector Privado, empleándose específicamente en las empresas pesqueras donde ejecutan tareas de fileteo y procesamiento de pescados, así como en el trabajo de la construcción en Cooperativas conformadas por migrantes bolivianos que llegaron a reunir cierto prestigio y capital para organizar las empresas contratistas. Finalmente, se emplean también en el Trabajo por cuenta propia con la instalación de servicios de transportes, taxis, peluquerías, tiendas, restaurantes y almacenes. Siendo la Feria denominada "Chacaltaya" (camino frío en aimara), ubicada en el ingreso al barrio 3 de Febrero, un lugar donde existe gran concentración de comercios minoristas cuyos propietarios y propietarias son migrantes bolivianos.

\footnotetext{
6 Entrevista realizada a Viviana, 28 de agosto de 2014, Caleta Olivia.

7 Ver: http://agenciacaletaolivia.org.ar/images/stories/ agencia/descargas/documentos/Plan_Estrategico_ de_Desarrollo_Productivo_Caleta_Olivia_2009.pdf (Consulta realizada el 16 de octubre de 2014).
}

La forma de ingresar al mercado de trabajo por parte de los migrantes bolivianos en Caleta Olivia nos permite observar que a pesar de las fronteras entre los nativos y los "recién llegados", se generan una serie de intersticios que "los nuevos" logran considerar como válidos para su agenciamiento. En el sentido de que las estructuras no solo oprimen y constriñen, sino que también dan poder y habilitan/posibilitan (Grossberg, 1992; Boivin et al., 2004), y nos recuerdan el carácter habilitante y constrictivo de las estructuras (Giddens, 1995). En cuanto a la categoría nativa "Nacidos y Criados", está representada por los catamarqueños. Ocupan también un lugar central los chilenos, quienes pueden llegar a ser considerados como los "locales" de Caleta Olivia, si bien existen familias descendientes de los grupos de migrantes europeos que forman parte de los sectores económicos más importantes de la ciudad. Pero no parecen formar parte de los grupos que "compiten" por los puestos de trabajo, ni por determinados sectores del espacio físico en la ciudad, entonces no forman parte de las alterizaciones (Briones, 1998) en relación a los grupos migrantes limítrofes e internos.

En varios aspectos, las comunidades quechuas provenientes de Bolivia presentan problemáticas similares. Podríamos decir que, desde la década de 1960 en adelante, se acentuó un proceso que marcaba el desplazamiento de los migrantes limítrofes hacia áreas no específicamente fronterizas. Los ajustes económicos que profundizaron la crisis del sector rural en las economías latinoamericanas, en el caso boliviano, generaron el desplazamiento hacia distintos lugares del mundo y en particular a las urbes de Argentina, principalmente Buenos Aires, Córdoba, Mendoza, entre otros. Sin embargo, en este proceso de desplazamiento, fueron tornándose atractivas determinadas zonas que demandaron mano de obra para actividades frutihortícolas, o bien diversos mercados de trabajo como la construcción y, en el sur patagónico, el sector pesquero. De acuerdo a los datos del Censo 2010, se contabilizaron alrededor de 1.800.000 extranjeros en la Argentina, lo cual representa el $5 \%$ de la población total. Dentro de los grupos migrantes, podríamos decir que se produjo una latinoamericanización, siendo el grupo de paraguayos el más numeroso $(30 \%)$, y el de bolivianos el segun- 
do en importancia $(19 \%$ del total de extranjeros), seguidos por los chilenos, peruanos e italianos (Sassone, 2012).

Sin embargo, los migrantes provenientes de Bolivia han adquirido socialmente una visibilidad mayor que otros grupos, lo cual se refleja en los estudios sociales que refieren a este grupo. Podemos mencionar sucintamente algunos de los análisis que investigaron a los migrantes bolivianos en relación a su conformación como comunidad transnacional en el caso horticultores en la provincia de Buenos Aires (Benencia, 2006), y de su asociatividad (Pizarro, 2008). Un esfuerzo por considerar en la perspectiva de análisis tanto a la sociedad de origen de los bolivianos como a la receptora, se encuentra en el trabajo de Zalles Cueto (2002). Otro grupo de trabajos aborda a los migrantes bolivianos en sus diferentes esferas y manifestaciones, de acuerdo a los tipos de sociedades "receptoras" (Caggiano, 2003, 2006). Si bien la mayor parte de los análisis acerca de los migrantes bolivianos apunta a explicar las situaciones de discriminación, los investigadores consideran que se desarrolla un sentido "pragmático" de las identificaciones etnonacionales, y el "ser extranjero" adquiere diversas connotaciones de acuerdo a la situación contextual y relacional (Grimson, 1999; Giorgis, 2004). Es este sentido dinámico de las identificaciones concebidas desde sus marcos relacionales el que será recuperado en el abordaje del problema de la experiencia de los migrantes quechuas provenientes de Bolivia en Caleta Olivia.

\section{Territorialización quechua en el "3 de Febrero"}

En un esfuerzo por problematizar nociones y categorías predominantes en el análisis del territorio urbano, tales como "barrio", "asentamiento", "villa miseria", entre otras, nos propusimos ingresar y privilegiar en primer término la comprensión del modo de incorporarse en el territorio por parte de los migrantes quechuas bolivianos que residen en un sector del denominado barrio 3 de Febrero. La territorialidad que se construye en "3 de Febrero" es distintiva con respecto a otros grupos migrantes que no poseen un componente indígena mayoritario, como el caso que aquí presentamos. Podemos citar el caso de los migrantes chilenos, que si bien numéricamente son mayoritarios (ver Cuadro $N^{\circ} 1$ ), no constituyeron "barrios chilenos", sino que fueron adoptando formas de urbanizaciones similares al resto de los grupos de Caleta Olivia. En cambio en el caso de los migrantes quechuas que se asentaron en el "3 de Febrero", la territorialización de sus prácticas generó un modo de apropiación del espacio que en sí mismo constituye su fortaleza como grupo étnico. Desde el "3 de Febrero", despliegan y desarrollan prácticas ancestrales que remiten a la Pachamama, de agradecimiento y peticiones a la Madre Tierra. En cada celebración bendecir la tierra con chicha significa devolver a la tierra, venerarla y reconocerla como dadora de bienestar y esperanza.

Recuperamos aquí una noción de territorio como "el espacio apropiado y valorizado por los grupos sociales [...], la resultante de la apropiación y valorización del espacio mediante la representación y el trabajo" (Carballo, 2009: 25). Los migrantes bolivianos Ilegaron en el año 1996 al lugar que hoy habitan -luego de trabajar estacionalmente en Las Heras (Santa Cruz) y/o Puerto Madryn (Chubut)-, consideraron todas las posibilidades evaluando no solo las características físicas del terreno, que por cierto eran inaccesibles por la altura de alrededor de 70 metros sobre el nivel del mar, con pendientes pronunciadas e irregularidades en el terreno; sino que sumaron las averiguaciones respecto al estado legal de las tierras. Así recuerda Juan, uno de los primeros que llegaron al lugar:

"Encontré varios terrenos [...]. Esto era pozo y alto, hicimos movimiento de suelo [...]. Una señora nos dijo que el dueño era ADOSAC [...], éramos cuatro familias, entonces usurpamos, armamos comisión de obra, 11,74 metros por 30 metros de fondo tiene cada terreno. Yo soy el autor" 8 .

Luego de ocupados los terrenos comenzaron los trámites para abonar el valor de los terrenos.

\footnotetext{
8 Entrevista realizada a Juan el día 30 de septiembre de 2014, Caleta Olivia.
} 


\section{El Centro de Residentes "Patria Grande": formación y participación en la territorialización del "3 de Febrero"}

Quien nos relató el modo en que fueron ocupando los terrenos del territorio hoy habitado por los migrantes quechuas en su mayor parte provenientes de Cuchupunata y Punata (Cochabamba, Bolivia), es uno de los "pioneros", tal como se refleja en el modo de enunciar y explicar cómo se dio el proceso de poblamiento del lugar. Al momento de llegar, consultaron a una vecina del barrio 3 de Febrero, ella les dijo que los terrenos eran de la Asociación de docentes de Santa Cruz (ADOSAC), pero que estaban desocupados. Luego de averiguar en el Consejo Deliberante Local, que los terrenos no tenían propietarios, solicitaron la ocupación y las autoridades advirtieron que por tratarse de extranjeros deberían realizar el trámite de "actuación de zona de fronteras". Las mediciones de los terrenos las realizaron ellos mismos, a cargo de Juan que es un profesional maestro mayor de obras universitario, con el cuidado de realizar mediciones en un "plano de igualdad" para todos los interesados que rápidamente de 4 familias de migrantes bolivianos pasaron a ser 20. Aplanaron los terrenos para comenzar a construir, adaptaron distintas partes del cerro para levantar cimientos. Trabajos que para los caletenses es comparable a los "ratones" que cavan sin parar, tal como nos comentó una vecina. Además contemplaron los espacios comunes, tal como el lugar destinado a la construcción del Centro de Residentes, la Iglesia y el centro de salud.

En estos aspectos es donde se resalta la planificación del asentamiento, reuniéndose las condiciones para que los terrenos fueran subdivididos en lotes y manzanas, con sus calles trazadas y espacios reservados para servicios esenciales, como el dispensario médico, la sede social de la organización, cancha de fútbol, entre otras. A estas proyecciones también se suma que, antes de la ocupación de las tierras, se deben realizar una serie de trabajos "de inteligencia". También se prevén las dimensiones del predio y se realiza una mensura provisoria que otorgará el número aproximado de lotes que saldrán de la subdivisión (Merklen, 1997). En este contexto también reúne las condiciones vinculadas a la acción política "politicidad" que genera la ocupación, los delegados y representantes del grupo que dialogan y negocian con los políticos locales, al punto que existe un mito en la ciudad de que "los bolivianos pusieron al Intendente". El apoyo al candidato constituyó un hecho de la realidad, pero en términos del padrón electoral debemos considerar que los migrantes bolivianos constituyen una minoría si comparamos, en particular, con el grupo de migrantes chilenos.

El actual presidente de la asociación "Patria Grande", no duda en afirmar su filiación con el gobierno de Evo Morales en Bolivia y con los gobiernos kirchneristas de Argentina, al primero por representar el "despertar" de lo indígena-campesino mediante la revolución social, y a los segundos por destrabar un problema histórico vinculado a la tramitación de documentación. Desde "Patria Grande", no solo se realiza la tramitación de documentación como representantes del Consulado Boliviano, sino que llevan adelante una serie de actividades que los posicionan ante la comunidad caletense como un grupo que reclama frente a situaciones de discriminación, tal como sucedió en diferentes ocasiones en el contexto de instituciones escolares que se negaban a reconocer los derechos que emanan de la Ley migratoria $N^{\circ} 25871^{9}$. Además, el Centro de Residentes participa activamente en la coordinación de campañas y programas del sistema de salud pública (Baeza, 2015).

Actualmente, el sector ocupado por los migrantes bolivianos en el barrio 3 de Febrero se encuentra en proceso de consolidar sus características barriales, a través del ingreso al Programa nacional de mejoramiento barrial (PROMEBA), y aunque se volverán a realizar las mensuras considerando la situación de ocupación actual, los trámites de los títulos de propiedad se encuentran en marcha. Desde la agencia estatal municipal se reconoce que gran parte de la comunidad boliviana se

\footnotetext{
9 Entrevista realizada al presidente del Centro de Residentes Bolivianos "Patria Grande", Caleta Olivia, 2 de junio de 2013. La Ley 25.871 fue sancionada por el Congreso en diciembre del año 2003, promulgada en el año 2004 y reglamentada en el año 2010. Básicamente la legislación actual garantizar el acceso al trabajo, y en el caso de los beneficios en materia de salud y educación es independiente de la regularidad en la documentación.
} 
encuentra con derecho de adjudicación y en otros casos bajo el dominio de propiedad de la tierra, concentrado sobre todo en un sector del barrio 3 de Febrero, pero que ha formado parte de la política de gobierno evitar dicha concentración, adjudicando terrenos dispersos en distintos lugares de la ciudad, tal como la denominada "zona de chacras". Las razones están vinculadas a la reglamentación con la cual se rige el gobierno local, que sostiene que un grupo de migrantes limítrofes no puede agruparse residencialmente en una ciudad que está dentro de una "zona de fronteras" 10

Sin embargo, ni "barrio", ni "asentamiento", son conceptos que reflejen determinadas dimensiones vinculadas a las experiencias vividas en relación al habitar el territorio del "3 de Febrero". Consideramos válido recuperar la noción de "construcción territorial", dado que el territorio no se constituye simplemente por la ocupación que un grupo hace de él, sino que es a partir del componente relacional que se activa un proceso de construcción territorial. Como lo precisa Carballo (2009: 28):

"Es entonces, el territorio un espacio apropiado, ocupado y dominado por un grupo social para asegurar su reproducción y satisfacer sus necesidades vitales, que pueden ser tanto materiales como simbólicas [...] El territorio no se reduce a su función instrumental, sino que además es también objeto de operaciones simbólicas y donde los actores proyectan su visión o representación del mundo cultural y social".

Una de las entrevistadas que residió en el "3 de Febrero" y que debió mudarse, ya que su hermana compró un terreno en la denominada "zona de chacras", recuerda con nostalgia sus días en "el 3": "se sentía uno como que estaba allá. Pero ya no había

\footnotetext{
10 Entrevista realizada a la Supervisora de Planificación Urbana de la Municipalidad de Caleta Olivia, 28 de agosto de 2014, Caleta Olivia, Santa Cruz. La inclusión de Caleta Olivia dentro de la "zona de frontera" refiere al hecho de ser una ciudad que se encuentra dentro de la franja marítima del océano Atlántico.
}

más lugar $[\ldots]^{\prime \prime 11}$. Esta afirmación nos lleva a reflexionar acerca del modo en que se construye el territorio quechua por parte del grupo de migrantes bolivianos, de qué modo llega a realizar un parangón entre "el habitar" en Cuchupunata o en Punata y el modo de habitar en "el 3 de Febrero". En este sentido, los migrantes quechuas provenientes de Bolivia, han logrado apropiarse del territorio al punto de generar esa familiaridad necesaria para que "los nuevos" que Ileguen a vivir o de visita nada les resulte extraño. Captar estas experiencias, sensaciones, difíciles de objetivar, pero que es necesario relatar, implica adoptar un tipo de análisis que "[incluya] las geografías emocionales y las experiencias múltiples de los lugares [...]" (Hirt, 2012: 69).

Por una parte, se encuentran marcas visibles en el espacio, que son posibles de observar, cuantificar, objetivar, tales como letreros de negocios de ropa, comidas y servicios de peluquería, que referencian el lugar de origen: Punata, Cochabamba, u otros que remiten a la religiosidad, tal como "Urkupiña" o "Copacabana". Por otra parte, existen también elementos posibles de ser captados a través de la percepción de los sentidos, como el sonido de la música de tinkus y otras producciones musicales que recuperan temas del folclore cochabambino, las conversaciones en quechua que es posible escuchar, los olores a las comidas "típicas" como picante de pollo, piquemacho, chicharrones, panes rellenos, entre otros platos que cada fin de semana se ofrecen en los restaurantes o bien en improvisados puestos callejeros. Finalmente, es destacable que las construcciones de las viviendas parecieran orientadas "a recibir" a las visitas, celebraciones de "corte de pelo", bautismos, aniversarios de bodas, velorios, entre otros eventos que denotan un modo diferente de pensar "el estar juntos" local. Las viviendas que construye el resto de la población local en general, son pequeñas y "cerradas", en cambio las viviendas que visité en el "3 de Febrero" parecen "invitar" a quedarse y compartir; alrededor de un salón central amplio sobre el cual se

\footnotetext{
11 Entrevista realizada a Daniela, 28 de agosto de 2014, Caleta Olivia.
} 
construye un "tinglado"12, se congregan las habitaciones, cocina, baño y demás dependencias del hogar.

Para los grupos nativos de Caleta Olivia, el progreso de los migrantes bolivianos es mirado con recelo. También entre los aimara que migran a El Alto en La Paz (Bolivia), el esfuerzo realizado en pos de la movilidad social refuerza la discriminación por parte de la sociedad local (Albó, 1992). Sus autos, camionetas, edificaciones de materiales perdurables -de dos plantas en algunos casos-, son observados desde el plano de superioridad que reproducen las alterizaciones mencionadas de sospecha hacia los venidos y quedados (vyq), y que los migrantes bolivianos parecieran "transgredir" cotidiana y afanosamente en procura de construir un modo de relacionalidad que busca en cierto modo saciar esa "eterna incompletud" del migrante, que la sociedad receptora pareciera no comprender. Sayad, desde su propia condición de emigrado, también identifica una serie de problematizaciones internas que expresa como

“[...] una forma de deserción y, en última instancia, de traición; siempre planea sobre la emigración algo parecido a una sospecha, la rodea una atmósfera de recelo interior que, salvo contadas excepciones, el emigrante procura no manifestar ni exteriorizar públicamente [...]" (Sayad, 2010: 24).

En cierto modo, los entrevistados relataron distintos modos de dar a conocer sus "nuevas vidas" en el sur argentino, para que el desconocimiento sea superado por la comprensión del significado de la migración. Uno de los modos está representado por traer a sus padres, sobre todo a las madres, pero es un proyecto que en general fracasa porque no logran acostumbrarse al nuevo hábitat y deciden regresar al lugar de origen. Encontramos dos casos en que las abuelas no lograron acostumbrarse a la vida en Caleta Olivia, y otros dos en que mujeres longevas viajaron desde Cochabamba para celebraciones espe-

\footnotetext{
12 Un "tinglado" es un cobertizo improvisado con maderas, hierros y otros materiales que se construye para cubrirse de las inclemencias climáticas.
}

ciales como casamientos y bautismos. Quizás sea este uno de los motivos del denodado esfuerzo por apropiarse y brindar significado al espacio del "3 de Febrero", si se logra el parecido al lugar de origen como Punata o Cuchupunata, en las próximas visitas de los progenitores desearán quedarse con la familia.

También debemos considerar otros factores que contribuyen al proceso de estructuración del grupo de migrantes quechuas provenientes de Bolivia, entre los que se encuentra contar con profesionales médicos que escuchan y dialogan con ellos, en particular un médico formado en salud comunitaria que maneja un concepto de salud no tradicional y que, en cierto modo, contribuye a mitigar los efectos que el sistema de salud puede tener sobre la población en general, y en particular sobre los grupos migrantes (Baeza, 2013b). Iniciamos aquí el análisis del agenciamiento territorial que lleva adelante el grupo de migrantes quechuas en Caleta Olivia, no solo a partir de sus prácticas políticas y socioculturales a nivel local, sino su ubicación en un plano que transciende y se ubica en lo transnacional. Sin embargo, consideramos que es necesario seguir profundizando esta línea de análisis, en posteriores abordajes donde continuaremos el estudio en aspectos que aquí se mencionan, tales como la relación entre género y territorio.

\section{Las prácticas religiosas como producción territorial en el "3 de Febrero"}

Uno de los pilares de la territorialidad quechua en el "3 de Febrero" es la religiosidad católica, la cual comenzó a expresarse "desde los primeros tiempos" de llegada de los migrantes que instalaron santuarios en las casas particulares, trajeron desde Bolivia a la Virgen de Urkupiña y la Virgen de Copacabana. En el último caso, para el traslado de la réplica, intervinieron distintos grupos de migrantes católicos, sacerdotes y también el intendente de la ciudad, para colaborar en los trámites que debieron realizarse para pasar los controles fronterizos. Hacia el año 2003, la Virgen de Copacabana estaba entronada en la capilla Virgen del Valle y, en ocasiones, tenía estadías en los hogares de los migrantes. Del mismo modo, las clases de catecismo para comunión y confirmación se realizaban en distintos hogares alternativamente. Sin 
embargo, el proyecto de construir el edificio para la Iglesia "competía", en cierto modo, con el destinado al Centro de Residentes bolivianos. Finalmente, terminó predominando el grupo que impulsó la construcción de la Iglesia.

El 16 de agosto de $2014^{13}$ se inauguró la Iglesia "Virgen de Copacabana", construida con el dinero y el trabajo de la comunidad boliviana, con aportes individuales y de las cooperativas de trabajadores de la construcción y de las pesqueras. El edificio fue emplazado en la parte más alta del "3 de Febrero", desde donde se tiene una vista panorámica de toda la ciudad y el mar que la bordea. La fiesta de inauguración duró tres días consecutivos, en coincidencia con el aniversario de la Virgen de Urkupiña y de San Juan Bosco, patrono salesiano en la Patagonia. El apoyo del Obispado de Santa Cruz, y en particular del sacerdote Néstor Zubeldía quien posee experiencia con migrantes paraguayos en asentamientos de la ciudad de La Plata (Buenos Aires), fue central para que los migrantes quechuas originarios de Bolivia pudiesen canalizar una demanda que, para ellos, no solo significaba poder practicar un modo de ser católico "no tradicional", sino que representaba un símbolo en la construcción territorial del espacio que habitan. El sacerdote, por su lado, considera que debió adaptarse a otra realidad, ya que venía de la austeridad de los paraguayos de La Plata, devotos de la Virgen de Cacupé y hablantes guaraníes. Al Ilegar a Caleta Olivia, debió dedicarse a bendecir autos nuevos, escuchar quechua, adaptarse a nuevas formas de entender el tiempo y a horarios más laxos, así como usar estola de aguayo ${ }^{14}$ y sobre todo comprender un catolicismo "menos formal"15, tal como

13 Además de coincidir con las celebraciones de la Virgen de Urkupiña, en Patagonia, regularmente se realizan en conjunto con la celebración del día de la Independencia de Bolivia, el 6 de agosto.

${ }^{14}$ La estola es una tela similar a una "bufanda" que forma parte del vestuario que utilizan los sacerdotes católicos para las ceremonias religiosas. Y el aguayo es una tela de colores múltiples y llamativos que actualmente son confeccionados industrialmente, pero en sus orígenes eran artesanales. Son utilizadas para muchas funciones, como adornos, para transportar bebés, ropa, entre otras pertenencias.

15 Un caso cercano al de los migrantes católicos bolivianos, podemos encontrarlo en el barrio Laprida él lo definió ${ }^{16}$. A lo anterior, se suma también la incorporación de una catequista punateña en la enseñanza de catecismo, quien posee formación profesional en educación católica, enseña a rezar en castellano y quechua, y se propuso culminar con la obra de construcción de la Iglesia, y repartiendo sus días entre el trabajo con el fileteado de pescado y las clases de catecismo similares a las que se reciben en Punata, promoviendo "la costumbre boliviana es rezar"17. La catequista considera que este modo de rezar con profundos sentimientos católicos, necesita de ser demostrado y enseñado de generación en generación.

Básicamente, se practica una estética diferente a la que es posible observar en la formalidad del catolicismo patagónico, los migrantes bolivianos no escatiman en gastos monetarios para las celebraciones en honor a sus vírgenes. El culto se practica hacia el interior de la Iglesia con abundante ornamentación de flores y colores, aguayos en el altar, con la bendición de las chuspas ${ }^{18}$ que representan el culto a la abundancia. Se pide por bienestar económico en el transcurso del año, en un marco que contempla también la nacionalidad de origen y la adoptiva argentina. Así, en el bolso de aguayo del año 2014, estaban presentes: dos banderas que simbolizaban a Argentina y Bolivia, un billete de dólar reconociendo la moneda de cambio "fuer$t^{\prime \prime}$ y una tinaja con granos. Este despliegue de colores que se realiza en el marco de las ceremonias religiosas apunta a recrear aspectos de la "vida en Punata", resignificadas en el transcurso del proceso migratorio y "nuevas" para quienes, como niños y jóvenes, no poseen registros memorísticos que si poseen adultos y ancianos. Los ancianos y adultos desean transmitir a las nuevas generaciones

de Comodoro Rivadavia (Chubut), con la presencia de migrantes catamarqueños que se emplearon en la empresa estatal YPF, y que actualmente celebran cada año el aniversario de la Virgen en el marco del "Festival de la Fe y la Cultura"; pero que posee otras características vinculadas a las diferencias entre ambos tipos de grupos migratorios.

16 Entrevista al sacerdote Néstor Zubeldía, Caleta Olivia, 18 de agosto de 2014.

17 Entrevista a Ximena, Caleta Olivia, 10 de septiembre de 2014.

${ }^{18}$ Es una bolsa de tela (en este caso de aguayo) que sirve para transportar hoja de coca u otros elementos. 
el modo en que se desarrollan las misas, comuniones, y entre otras ceremonias religiosas como las de matrimonios, que para la comunidad católica quechua poseen una serie de significados que transcienden a la formalidad de adquirir y "cumplir" con un mandamiento religioso (Figura $\mathrm{N}^{\circ}$ 2).

Figura $\mathrm{N}^{\circ} 2$

Obispo y sacerdote de Santa Cruz posan frente al altar, junto a integrantes de una fraternidad y su pasante



Fuente: Portal Voces y Apuntes, Caleta Olivia, 15 de agosto de 2014. Cedida por el propietario del Portal Voces y Apuntes.

El sacerdote Néstor oficia de "intérprete" de un tipo de catolicismo donde ve "lo unido que va lo religioso con lo popular [...]. Yo los cargo y les digo que dejaron vacía la capilla de San Juan Bautista de Punata en Cochabamba [...]. Cuando Ilegué, Ximena daba catequesis en las casas [...], ellos decían: 'nosotros no vamos a progresar si no tenemos Iglesia'"19. En cierto modo, la edificación de la Iglesia en el "3 de Febrero" puso fin a la incomodidad de no poder expresar el modo de practicar el catolicismo entre los migrantes bolivianos, sumado a que los niños y niñas que debían asistir a otras iglesias al catecismo eran molestados con robos, "peajes" y diversos problemas en el tránsito a otros barrios. Por último, es destacable el sentido que otorga este grupo de migrantes al significado de tener un edificio para el culto, tal como

\footnotetext{
${ }^{19}$ Entrevista al sacerdote Néstor Zubeldía, Caleta Olivia, 18 de agosto de 2014.
}

se encuentra simbolizado en la chuspa: fe y progreso económico van unidos. El resto de las edificaciones, como las instalaciones para el Centro de Residentes Bolivianos o el centro de salud, serán posibles a partir de saldar "la deuda" con las Vírgenes de Copacabana y Urkupiña.

Las prácticas de fraternidades, bailes y desfiles, asociadas a las celebraciones religiosas se desarrollan al aire libre, donde se permite mayor presencia de los colores, la música, las comidas y sobre todo expresiones de alegría y festejo. Cada fraternidad se turna para presentar los bailes que durante un año se fueron practicando, mejorando y preparando para la celebración. De modo ingenioso, llegan a reproducir las representaciones de Cochabamba, comprando trajes en Bolivia, confeccionando otros, o bien alquilando a grupos migrantes bolivianos de otras zonas del país. Todas las opciones mencionadas requieren de abultadas inversiones de dinero. Quien oficia de locutor comunica en caste- 
Ilano y quechua los distintos momentos de la celebración a los presentes. En estas prácticas religiosas, vemos integrarse mujeres $y$ hombres de todas las edades, donde destaca la presencia de jóvenes globalizados en sus modos de vestir y hablar, pero que en este espacio religioso se identifican de tal modo que en ocasiones asumen roles centrales en las celebraciones. En este sentido, coincidimos con Carballo al observar que, en estas geografías religiosas, se reconstruyen "[...] nuevas espacialidades, mentalidades, imaginarios, valores y comportamientos que resultan en cambios y recomposiciones religiosas del espacio" (Carballo, 2009: 38).

Sin duda, la realización de las celebraciones religiosas moviliza entre los migrantes quechuas de Bolivia una serie de prácticas tales como el idioma, las comidas, los bailes, los colores, la música, las fotografías y filmaciones de los eventos, los viajes de quienes asisten desde otros lugares de Patagonia a la celebración, entre otras inversiones que parecieran generar cierto placer. Resulta interesante recuperar aquí una reflexión de Rita Segato acerca del sentido latinoamericano de la acumulación de capital en el contexto de mercados locales y regionales donde, como en el caso andino, se puede llegar a adquirir una riqueza considerable sin "el fin último de la capitalización, sino teniendo como meta la vida y la fiesta como expresión de la vida" (Segato, 2013: 7).

Relacionalidad y "juego" de escalas desde el territorio del "3 de Febrero"

La celebración de la vida es lo que pudimos observar en uno de los eventos familiares que tuvimos la ocasión de compartir, en que una de las familias que reside en la calle Cabo Vírgenes celebraba las bodas de algodón de una de sus hijas para festejar el primer año de matrimonio. Todo ello en una especie de réplica de lo que fue la celebración de la boda, con un asombroso despliegue de ornamentación con cuadros, manteles, representaciones de cisnes, todo en la rama de los rosas y blancos, mujeres y hombres, niños, jóvenes y adultos, elegantemente vestidos. Una vez que se congregaron los familiares cercanos del matrimonio, un diácono de la ciudad los bendijo y dio un sermón alusivo resaltando el papel de lo que significa estar "acompañado" de la convivencia, del deseo de "estar juntos". Luego de la parte formal de la ceremonia, todos compartieron un almuerzo, con abundante picante de pollo, gaseosas y chicha de maíz. Nos retiramos a las 17.00 hs., pero la sensación fue que "la fiesta recién comenzaba", luego venía la torta y el baile animado desde la locución de "Radio Radiante FM" (Notas de campo, Domingo 21 de septiembre de 2014).

La mencionada radio fue instalada, a fines de 2013, por una familia de la comunidad de migrantes y cuenta con el aval del Centro de Residentes Bolivianos "Patria Grande", asociación a través de la cual iniciaron la tramitación del reconocimiento oficial de la radio, en el marco de la denominada "Ley de medios audiovisuales" que se encuentra vigente en la actualidad. Aunque no profundizaremos aquí en el impacto que tienen las emisiones de "Radio Radiante FM", no podemos dejar de mencionar que sus programas, en algunos casos son bilingües (quechua y castellano). Las emisiones radiales fortalecen los vínculos y relaciones entre los migrantes quechuas que ahora cuentan con un espacio de intercambio y escucha permanente. Por otra parte, al poder ser escuchada a través de internet, amplía los lazos de comunicación al resto de las comunidades de migrantes bolivianos y del país de origen. El emprendimiento radial da cuenta de un conocimiento técnico acumulado, además del capital económico que fue empleado para la adquisición de los equipos, como la antena entre otros elementos fundamentales para el montaje. El sostén económico para que el proyecto se prolongue en el tiempo está dado a través de su faz comercial, con la venta de publicidades y avisos. Aquí es donde el emprendimiento radial del "3 de Febrero" se emparenta con otros similares que surgieron en Buenos Aires en los últimos años, caracterizados por su complejidad donde convergen dimensiones económicas y sociales, debido a que son radios gestionadas por y para migrantes bolivianos, que poseen su faz étnica, cultural y comercial (Blasco, 2014). "Radiante FM" oficia como constructora de lazos territoriales clave para no solo fortalecer lazos familiares y de paisanaje local, sino reduciendo distancias con el lugar de origen, acercando noticias, eventos y sonidos diversos a través de la red de internet. 
La radio nos permite observar el funcionamiento de la imbricación de escalas que se produce en el territorio del el "3 de Febrero". En este sentido, las escalas se producen como formas de articulación que pueden incluir el vecindario, lo local, estatal, regional, nacional y mundial. "La región se convierte, por lo tanto, en territorialización en una determinada escala geográfica" (Harvey, 2007: 243). Así, la territorialización del "3 de Febrero" nos permite observar de qué modo un grupo que en la escala de alteridades locales es subordinado, en el agenciamiento territorial podemos ubicar sus manifestaciones y prácticas en las distintas escalas que interactúan local y globalmente. La imbricación de distintas escalas nos permite entender el modo en que se articulan y conectan espacios domésticos y locales como pueden ser las ferias Atahualpa y Chacaltaya, con los circuitos y flujos de mercados nacionales y globales. También en "FM Radiante" es posible observar el reescalamiento, donde la radio opera como productor de escalas que nos remite al fenómeno de la glocalización, en el sentido que se intensifican las formas globales de "conectividad" a través de las comunicaciones, desplazamientos y circulación de bienes, imágenes, ideas (Robertson y Giulanotti, 2006).

En este sentido, nuestro caso de análisis nos permite observar que lo local y lo global lejos de oponerse y de presentarse en forma dual, se fusionan e integran de modo complejo. A partir de estas configuraciones del lugar podemos recuperar la noción de "políticas del lugar" (Harcourt y Escobar, 2007), para analizar el modo en que estas mujeres construyen territorio indígena. En el caso de las mujeres de las ferias se destaca su rol cotidiano, como articuladoras de espacio mediante, la seguridad alimentaria, la recreación de lugares, y la formación de redes. Al contrario, de la visión que podría observarlas como "víctimas de la globalización", en este caso las vemos crear y controlar espacios. Desde sus hogares, su habitar y sus cuerpos, lejos de estar ubicadas en la esfera privada, desarroIlan sus prácticas en lo público y social. Así la "noción de políticas de lugar amplía las visiones respecto a lo político y la política, entendiéndolos como apuestas y prácticas surgidas de condiciones particulares en las que entran a participar aspectos considerados del ámbito privado "no político" (Garzón, 2008).
Estas conexiones entre el territorio de origen y el nuevo territorio, al contrario de generar rupturas generan una serie de acercamientos, contactos y nuevos lazos territoriales que fortalecen vínculos y pueden generar nuevos modos de transmisión de saberes y modos de manifestar la presencia de los migrantes quechuas en Caleta Olivia. El impacto que poseen las transmisiones radiales indígenas, han sido estudiadas para el caso de Santiago de Chile, donde la programación mapuche posee un papel clave en el contexto de la migración rural-urbana en cuanto a la puesta en escena de un modo conversacional y dialógico que remite al ethos cultural y político mapuche (Cárcamo-Huechante y Paillan, 2012).

De modo similar, la Feria Atahualpa ${ }^{20}$, que se encontraba en el centro del " 3 de Febrero" antes de sufrir un incendio en el 2013, funciona actualmente en el ingreso al barrio $y$, en cierto modo, reproduce en microescala lo que es la feria de migrantes bolivianos de Escobar, donde se vende ropa, productos alimenticios, juguetes, entre otros productos (Pizarro, 2009: 447). Por las características del clima patagónico, esta feria funciona en un espacio cerrado y techado. Luego del incendio de la Feria Atahualpa, los locales comerciales se trasladaron a un edificio que se encuentra en el ingreso al "3 de Febrero" y su denominación es "Chacaltaya". Varias de las mujeres del "3 de Febrero" ubican sus puestos de venta de ropa en otros centros comerciales de Caleta Olivia, viajando regularmente a Buenos Aires para realizar las compras al por mayor para la reventa en la ciudad. La administración de la feria está a cargo de las

\footnotetext{
20 En la feria Atahualpa era posible encontrar locales comerciales de venta de alimentos vinculados a la dieta originaria sobre todo de Punata, con legumbres, condimentos y productos que no se encuentran comercializados a gran escala, otros locales dedicados a la venta de artículos regionales del noroeste argentino o particularmente de Bolivia, como bienes industrializados pero que se asemejan a las artesanías con telas de aguayo, y otros locales cuyos artículos se comercializan desde Buenos Aires, donde se adquieren en viajes especiales para la compra. Debemos destacar que el comercio desarrollado por las mujeres migrantes se encuentra en un proceso de expansión, a partir de la instalación de locales en el centro de la ciudad, en galerías comerciales dedicadas sobre todo a la venta de ropa.
} 
autoridades del Centro de Residentes Bolivianos. Uno de los primeros presidentes de la asociación recuerda que fue una necesidad crear el Centro, básicamente necesitaban una institución que convoque a determinadas celebraciones como el Día de la Independencia de Bolivia, o bien se encargue de tramitar soluciones como las de los servicios públicos ante las autoridades municipales, entre otras cuestiones que llevaron a la iniciativa de agruparse. Como denominación consideraron la sugerida por un abogado de la ciudad con quien compartían diversas peticiones y tareas: "Patria Grande" 21 .

\section{A modo de cierre}

A lo largo del artículo, intentamos realizar un aporte a las investigaciones que se enmarcan en las denominadas geografías indígenas, considerando las características que asume un grupo indígena migrante que proviene de una zona rural de Bolivia. En una primera sección, destacamos las similitudes y diferencias de las migraciones de distintos grupos indígenas y con adscripción nacional en Bolivia, marcando el desplazamiento hacia el sur de Argentina, como parte de un movimiento vinculado a las características que asume el capitalismo actual. En una segunda sección, consideramos la organización y estrategias territoriales del grupo de migrantes quechuas en Caleta Olivia, nucleados en el Centro de Residentes "Patria Grande". En este ejercicio, destacamos sus prácticas religiosas como una de las herramientas de territorialización, junto con otras como las prácticas comerciales y el uso de la radio, que nos permitieron observar la imbricación de escalas locales, nacionales y globales que se manifiestan en el proceso de territorialización en el "3 de Febrero". A lo largo de nuestras visitas a esta población, pudimos observar el sentido que poseen las prácticas que el grupo de migrantes desarrolla cotidianamente, por ejemplo

\footnotetext{
21 De acuerdo a la información que nos otorgó el entrevistado, la denominación está vinculada a las ideas socialistas del abogado. Entrevista realizada a Julio, Caleta Olivia, 30 de septiembre de 2014 Pero también tenemos que mencionar que "Patria Grande" es el título del programa de regularización documental para migrantes que puso en marcha el Presidente Néstor Kirchner en el año 2006.
}

cuando ocupan una esquina o las veredas y ubican sus puestos de ventas de comidas "típicas", al recrear la venta de jugos y golosinas al estilo cochabambino improvisando puestos callejeros. Y una vez al año en el mes de agosto, con un sentido ritual indígena, en cada celebración en honor a la Virgen de Copacabana y a la de Urkupiña, se produce el momento de mayor contacto con la Madre Tierra, en este modo de práctica católica con fuerte impronta indígena, los y las migrantes quechuas sienten recrear la unión y la apropiación al territorio. Lejos de las prácticas agrícolas, en una sociedad industrial, sienten la necesidad y el deber de agradecer y recrear el vínculo indígena con la Pachamama en el "3 de Febrero".

\section{Coincidimos en este sentido con que}

"se puede abandonar físicamente un territorio, sin perder la referencia simbólica y subjetiva al mismo a través de la comunicación a distancia, la memoria, el recuerdo y la nostalgia. Cuando se emigra a tierras lejanas, frecuentemente se lleva 'la patria adentro'" (Giménez, 1996: 15).

En este estudio, contribuimos a enriquecer la mirada acerca de lo que sucede con la territorialización en un contexto migratorio, a través de un proceso de reetnicización de un grupo de migrantes quechuas originarios de Bolivia en el "3 de Febrero". Estos migrantes conforman así un grupo globalizado, que logra posicionarse políticamente frente a procesos de institucionalizaciones complejas donde "territorio, autoridad y derechos" se constituyen a través de procesos específicos y surgen de luchas e intereses conflictivos (Sassen, 2006). En nuestro caso particular, el modo de obtener las tierras en el "3 de Febre-

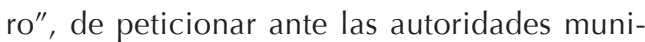
cipales, de gestionar el mejoramiento barrial, muestra a estos migrantes como un grupo que puja por ejercer su ciudadanía.

El sector que habitan los y las migrantes quechuas de Bolivia puede ser visto como un territorio donde la porosidad de sus fronteras ha permitido la inscripción y apropiación del mismo, en diferentes dimensiones y escalas, a partir de imbricaciones complejas entre lo local y lo nacional, en que mujeres y hombres quechuas de distintas generaciones producen 
sus propias subjetividades migrantes. Así, el "3 de Febrero" parece otorgar a la relación hombre-naturaleza un significado particular que incluye lazos de parentesco, de vecindad, de amistad, que incluye el proceso de poblamiento y ocupación del espacio, pero que también lo trasciende y enlaza a migrantes quechuas de Bolivia que residen en otros sectores de Caleta Olivia y la región patagónica. En este sentido, será interesante, para futuras investigaciones, seguir incursionando en las prácticas de este colectivo indígena en relación a la territorialidad que despliega y ejerce en la ciudad de Caleta Olivia y más allá, en un territorio transnacionalizado. Necesitamos continuar en la línea de análisis que destaque y recupere el modo en que estos grupos viven el espacio a partir de sus prácticas con las que construyen el territorio que habitan.

\section{Referencias bibliográficas}

ALBÓ, X. Bases étnicas y sociales para la participación Aymara en Bolivia La fuerza histórica del campesinado In: Ciudades de los Andes: Visión histórica y contemporánea. Lima: Institut français d'études andines, 1992. Disponible en Internet:

http://books.openedition.org/ifea/2259

BAEZA, B. Trabajadores migrantes bolivianos y paraguayos en la construcción. Comodoro Rivadavia, Chubut. Revista Trayectorias, 2013a, Año 15, Nº37, p. 31-52.

BAEZA, B. La memoria migrante y la escucha de los silencios en la experiencia del parto en mujeres migrantes bolivianas en Comodoro Rivadavia (Chubut, Argentina). Anuario Americanista Europeo, 2013b, № 11, p.179-197.

BAEZA, B. Tan cerca, pero tan distintas... Caleta Olivia (Santa Cruz) y Comodoro Rivadavia (Chubut). Mujeres migrantes bolivianas en el sistema de salud. En: XII Jornadas Nacionales de Historia de las Mujeres y VII Congreso Iberoamericano de Estudios de Género, Centro. Neuquén: Interdisciplinario de Estudios de Género, Facultad de Humanidades, Universidad Nacional del Comahue, 5, 6 y 7 de marzo de 2015.
BASTOS, S. y CAMUS, M. Los mayas de la capital. Un estudio sobre identidad étnica y mundo urbano. Guatemala: Editorial FLACSO, 1995.

BENEDETTI, A. Territorio: concepto integrador de la geografía contemporánea. En: SOUTO, P. (coordinador). Territorio, Lugar, Paisaje. Prácticas y conceptos básicos en geografía. Buenos Aires: Colección Libros de Cátedra, Facultad de Filosofía y Letras, Universidad de Buenos Aires, 2011, p. 31-82.

BENENCIA, R. El fenómeno de la migración limítrofe en la Argentina: interrogantes y propuestas para seguir avanzando. Revista de Estudios Migratorios Latinoamericanos, 19981999, Año 13/14, No 40-41.

BLASCO, L. Espacios radiofónicos creados, gestionados por y destinados a la población migrante residente en el AMBA. La complejidad de ser emprendimientos étnicos, culturales y comerciales a la vez. En: Ponencia presentada en el XI Congreso Argentino de Antropología Social, Rosario, del 23 al 26 de julio de 2014.

BOIVIN, M.; ROSATO, A. y ARRIBAS, V. Constructores de otredad. Una introducción a la Antropología Social y Cultural. Buenos Aires: Antropofagia, 2004.

BRIONES, C. La alteridad del "Cuarto Mundo". Una deconstrucción antropológica de la diferencia. Buenos Aires: Ediciones del Sol, 1998.

CAMUS, M. Ser indígena en Ciudad de Guatemala. Ciudad de Guatemala: Editorial FLACSO, 2002.

CAGGIANO, S. Fronteras múltiples: reconfiguración de ejes identitarios en migraciones contemporáneas a la Argentina. Cuadernos del Instituto de Desarrollo Económico y Social. Buenos Aires: IDES, 2003.

CAGGIANO, S. Lo que no entra en el crisol. Inmigración boliviana, comunicación intercultural y procesos identitarios. Buenos Aires: Editorial Prometeo, 2006.

CARBALLO, C. Repensar el territorio de la experiencia religiosa. En: CARBALLO, C. 
(coordinador). Cultura, territorios y prácticas religiosas. Buenos Aires: Prometeo Libros, 2009, p. 19-42.

CÁRCAMO-HUECHANTE, L. y PAILLAN, E. Taiñ pu amulzugue egvn: sonidos y voces del Wajmapu en el aire. En: COMUNIDAD DE HISTORIA MAPUCHE. Tai iñ fijke хipa rakizuameluwün. Historia, colonialismo y resistencia desde el país Mapuche. Temuco: Ediciones Comunidad de Historia Mapuche, 2012, p. 341-358.

CLAVAL, P. El enfoque cultural y las concepciones geográficas del espacio. Boletín de la A.G.E., 2002, № 34, p. 21-39.

DELEUZE, G. y GUATTARI, F. Mil Mesetas. Capitalismo y esquizofrenia. Valencia: Pretextos, 1988.

DI MEO, G. Géographies tranquilles du quotidien: une analyse de la contribution des sciences sociales et de la géographie à l'étude des pratiques spatiales. Cahiers de géographie du Québec, 1999, Vol. 43, №118, p. 75-93.

GARZÓN, M. El lugar como política y las políticas de lugar. Herramientas para pensar el lugar. Signo y Pensamiento, 2008, Vol. XXVII, No 53, p. 92-103.

GIDDENS, A. La constitución de la sociedad. Bases para la teoría de la estructuración. Buenos Aires: Amorrourtu Editores, 1995.

GIMÉNEZ, G. Territorio y cultura. Estudios sobre las Culturas Contemporáneas, 1996, № diciembre, p. 9-30.

GIORGI, M. La virgen prestamista. La fiesta de la Virgen de Urkupiña en el boliviano Gran Córdoba. Buenos Aires: Editorial Antropofagia, 2004.

GISSI, N. Segregación espacial mapuche en la ciudad: ¿negación o revitalización identitaria? Revista de Urbanismo, 2004, Nº 9, p. 30-40.

GRIMSON, A. Relatos de la diferencia y la igualdad, Los bolivianos en Buenos Aires. Buenos Aires: Eudeba, 1999.
GROSSBERG, L. We gotta get out of this place. Popular conservatism and postmodern culture. New York: Routledge, 1992.

HARCOURT, W. y ESCOBAR, A. Las mujeres y las políticas del lugar. México: Universidad Nacional Autónoma de México. Programa Universitario de Estudios de Género, 2007.

HARVEY, D. Espacios del Capital. Hacia una Geografía Crítica. Madrid: Akal, 2007.

HIRT, I. Mapeando sueños/soñando mapas: entrelazando conocimientos geográficos indígenas y occidentales. Revista Geográfica del Sur, 2012, Vol. 3, № 1, p. 63-90.

LINDON, A. Los imaginarios urbanos y el constructivismo geográfico: los hologramas espaciales. EURE, 2007, Vol. 33, No 99, p. 31-46.

LINDON, A. Las huellas de Lefebvre sobre la vida cotidiana. Veredas. Revista de Pensamiento Sociológico, 2004, Vol. 5, № 8, p. 39-61.

KARASIK, G. Plaza Grande y Plaza Chica: etnicidad y poder en la Quebrada de Humahuaca. En: KARASIK G. (compilador). Cultura e identidad en el Noroeste Argentino. Buenos Aires: CEAL, 1994, p. 90-112.

MARTÍNEZ BERRÍOS, N. Tierra, territorio y territorialidad mapuche: producción de espacio y formación de subjetividades. Revista Geográfica del Sur, 2012, Vol. 3, № 1, p. 37-62.

MERKLEN, D. Un pobre es un pobre. La sociabilidad en el barrio: entre las condiciones y las prácticas. Sociedad, 1997, № 11, p. 21-64.

MOLINA, R. Reconstrucción de los Etnoterritorios. En: INSTITUTO DE ESTUDIOS INDÍGENAS. Tierra, Territorio y Desarrollo Indígena. Temuco: Universidad de La Frontera, 1995, p. 111-118.

PIZARRO, C. Ciudadanos bonaerensesbolivianos: activismo político binacional en una organización de inmigrantes bolivianos 
residentes en Argentina. Revista Colombiana de Antropología, 2009, Vol. 45, p. 431-467.

RINCÓN GAMBA, L. Ser de acá o ser de allá no debería ser requisito. Nativos e inmigrantes en Santa Cruz, Patagonia austral argentina: territorios y sujetos por una ciudadanía universal para la reproducción ampliada de la vida de todos. Bogotá-Buenos Aires: Tesis de Maestría en Economía Social, Universidad Nacional de General Sarmiento (UNGS), Instituto del Conurbano (ICO), Maestría en Economía Social (MAES), 2012.

ROBERTSON, R. y GIULIANOTTI, R. Fútbol, Globalización y Glocalización. Revista Internacional de Sociología, 2006, Vol. 64, № 45 , p. 9-35.

SASSEN, S. Hacia una proliferación de ensamblajes especializados de territorio, autoridad y derechos. CDC, 2006, Vol. 23, N ${ }^{\circ}$ 62, p. 97-114.

SASSONE, S. Bolivianos en la Argentina: entre la precarización laboral y el empresariado étnico. Revista Fénix, 2012, № 21, p. 96-101.
SAYAD, A. El retorno, elemento constitutivo de la condición del inmigrante. Revista Empiria, 2010.

SEGATO, R. Aníbal Quijano y la Perspectiva de la Colonialidad del Poder. Revista Casa de las Américas, 2013, № 272.

SMITH, N. La nueva frontera urbana. Ciudad revanchista y gentrificación. Madrid: Traficantes de sueños, 2012.

TSING, A. Friction. An Ethnography of Global Connection. Princeton: Princeton University Press, 2005.

VOCES Y APUNTES. El Obispo celebró la misa inaugural de la Capilla de la Virgen de Copacabana. 16 de Agosto de 2014. Disponible en Internet:

http://www.vocesyapuntes.com/ nuevo/index.php/noticias/deportes/7607-2014-08-16-22-40-35

ZALLES CUETO. El enjambramiento cultural de los bolivianos en la Argentina. Revista Nueva Sociedad, 2002, № 178. 